Jan J. De Waele

J. Lipman

M. Akova

M. Bassetti

G. Dimopoulos

M. Kaukonen

D. Koulenti

C. Martin

P. Montravers

J. Rello

A. Rhodes

A. A. Udy

T. Starr

S. C. Wallis

J. A. Roberts

\section{Erratum to: Risk factors for target non- attainment during empirical treatment with $\beta$-lactam antibiotics in critically ill patients}

Published online: 28 March 2015

(C) Springer-Verlag Berlin Heidelberg and ESICM 2015

The online version of the original article can be found under doi:10.1007/s00134-014-3403-8.

J. J. De Waele $(\bullet)$

Department of Critical Care Medicine, Ghent University Hospital,

De Pintelaan 185, 9000 Ghent, Belgium

e-mail: jan.dewaele@ugent.be

Tel.: +3293326219

J. Lipman · D. Koulenti - A. A. Udy - T. Starr ·

S. C. Wallis - J. A. Roberts

Burns Trauma and Critical Care Research Centre,

The University of Queensland, Brisbane, Australia

J. Lipman · J. A. Roberts

Royal Brisbane and Women's Hospital, Brisbane, Australia

\section{Akova}

Hacettepe University Hospital, Ankara, Turkey

M. Bassetti

Azienda Ospedaliera Universitaria Santa Maria della Misericordia, Udine, Italy

G. Dimopoulos

Attikon University Hospital, University of Athens Medical School, Athens, Greece

M. Kaukonen

Helsinki University Hospital, Helsinki, Finland

M. Kaukonen

Department of Epidemiology and Preventive Medicine, Monash University, Australian and New Zealand Intensive Care Research Centre (ANZIC RC), Melbourne, Australia
C. Martin

Hospital Nord, Marseille, France

P. Montravers

Centre Hospitalier Universitaire Bichat-Claude Bernard, Paris, France

J. Rello

CIBERES, Vall d'Hebron Institut of Research, Barcelona, Spain

A. Rhodes

St George's Healthcare NHS Trust and St George's University of London, London, UK

A. A. Udy

Department of Intensive Care and Hyperbaric Medicine,

The Alfred Hospital, Melbourne, VIC, Australia

\section{Erratum to: Intensive Care Med (2014) 40:1340-1351 DOI 10.1007/s00134-014-3403-8}

In the last sentence of the "Data collection" subsection of the Methods section, the commonly used daily dose of piperacillin $\left(\mathrm{DD}_{\mathrm{ICU}}\right)$ was incorrectly listed as $2 \mathrm{~g}$; the correct value is $12 \mathrm{~g}$. 